\title{
Comparison of Bread-Making Quality on Saccharomyces cerevisiae Strain YTPR1 Prepared in Different Conditions
}

\author{
Takeshi Nagai $^{1,2,3}$, Yasuhiro Tanoue ${ }^{4}$, Norihisa $\mathrm{Kai}^{5} \&$ Nobutaka Suzuki ${ }^{6}$ \\ ${ }^{1}$ Graduate School of Agricultural Sciences, Yamagata University, Yamagata, Japan \\ ${ }^{2}$ The United Graduate School of Agricultural Sciences, Iwate University, Iwate, Japan \\ ${ }^{3}$ Graduate School, Prince of Songkla University, Songkhla, Thailand \\ ${ }^{4}$ National Fisheries University, Yamaguchi, Japan \\ ${ }^{5}$ Graduate School of Engineering, Oita University, Oita, Japan \\ ${ }^{6}$ Nagoya Research Institute, Aichi, Japan \\ Correspondence: Takeshi Nagai, Graduate School of Agricultural Sciences, Yamagata University, Yamagata \\ 9978555, Japan. Tel: 81-235-28-2821. E-mail: nagatakenagatake@yahoo.co.jp; tnagai@tds1.tr.yamagata-u.ac.jp
}

Received: January 23, 2018 Accepted: February 24, $2018 \quad$ Online Published: March 15, 2018

doi:10.5539/jas.v10n4p47 URL: https://doi.org/10.5539/jas.v10n4p47

The research work was partly supported by JSPS KAKENHI Grant Number 25560032 and by a grant from the Elizabeth Arnold Fuji Foundation.

\begin{abstract}
The aim of study was to investigate bread-making quality on wild-type $S$. cerevisiae YTPR1 isolated from pear Red Bartlett fruits harvested in Yamagata, Japan, and was to compare its qualities on YTPR1 prepared in different conditions. Bread produced using frozen strain YTPR1 had a thin skin and crisp skin surface in crust, and had a moist and soft eat-feeling in crumb. Loaf was spread largely, but its bottom had relatively density. Loaf showed the same weight and volume, moisture, expansion ratio, specific volume, weight loss, and breaking force of crumb as that using commercially available dried yeast. In crust of loaf, $L^{*}$ value was higher but $a^{*}$ and $b^{*}$ values were lower than those of commercially available dried yeast. From results of brownness index, crust had a light brown color (golden brown color). In crumb, loaf was evaluated as appreciable in color difference. That is, loaf had an even baked color (desirable golden brown color). On the other hand, bread-making qualities on freeze-dried yeast, trehalose-addition yeast, glycerol-addition yeast, and L-glutamic acid-addition yeast were inferior to that on commercially available dried yeast. It concluded that high quality of bread with acceptable attributes could be produced using frozen yeast strain YTPR1 isolated from pear Red Bartlett fruits. However, these substances had not functions as cryoprotectant or cryosensitizer on yeast cells.
\end{abstract}

Keywords: bread-making, comparison, quality, Saccharomyces cerevisiae strain YTPR1

\section{Introduction}

Yeast for production of fermented foods such as breads, wines, and beers belong to Saccharomycetaceae. Generally, dried yeasts (baker's yeasts strain Saccharomyces cerevisiae) are widely used in bread making because of the long-term storage ability. It is increasingly necessary to make high quality of breads suitable for taste of modern consumers along with change and diversification of diet. That is, it is conceivable that it is useful to acquire the yeasts with different physiological properties from the nature and to improve the characteristics of superior strains using genetic and cellular engineering methods (Matsuda et al., 2005).

Wild-type yeasts possess characteristic aroma and assimilative ability associated with the growth environments such as flowers, fruits, leaves, and branches. Recently, development of breads using wild-type yeast is receiving a lot of attention in baking industries. For example, yeasts such as Shirakamikodama yeast (Shimosaka, 2011), Minowa yeast (Sekiguchi, 2008), Matebashii yeast, Kuchinashi yeast (Nagata, 2017), and Tokachino yeast (Oda et al., 2012) were separated and isolated, and then were utilized as yeast for bread making using bread flour. Among wild-type yeasts, Hoshino natural yeast is frequently used in bread making, but it could not be used as it is. So, it needs to prepare fresh yeast by pre-fermentation for $24-48 \mathrm{~h}$ after melting in tepid water. On the 
contrary, Shirakamikodama yeast can use without preparation of fresh yeast and pre-fermentation, and it is said that it is suitable for bread making using domestic flours. However, these are an extremely low number of wild-type yeast with highly baking quality as commercially available baker's yeast (Bell et al., 2001).

In recent years frozen-dough technique has been accepted in baking industries for supplying oven-fresh breads and for improving the working conditions of bakers. In this case, freeze and subsequent thawing of bread dough cause the injury in the yeast cells, causing lower the leavening ability of dough. In bread making, yeast cells are exposed to multiple stresses. There are many factors that affect tolerances on yeasts as follows: temperature (D'Amore et al., 1991; De Virgilio et al., 1994; Eleutherio et al., 1993; Panek et al., 1990; Slaughter \& Nomura, 1992), freezing (Coutinho et al., 1988; D’Amore et al., 1991; Gélinas et al., 1989), dehydration (Coutinho et al., 1988; Gadd et al., 1987; Pearce et al., 1989), desiccation (Hottiger et al., 1987; Takagi et al., 2000), hyperosmotic (D’Amore et al., 1991; Mackenzie et al., 1988), and ethanol (Takagi et al., 2005). Among them, freeze and drying tolerances on yeasts are important characteristics for bread making. In the above-described wild-type yeast, Shirakamikodama yeast can be used in frozen-dough bread-making method to possess freeze tolerance.

Recently, we succeeded in isolation of $S$. cerevisiae strain with high gassing power and ethanol productivity from pear Red Bartlett fruits harvested in Yamagata, Japan, and strain YTPR1 was identified as S. cerevisiae by its 28S rRNA sequence analysis (DDBJ/EMBL/GenBank Accession Number LC331262) (Nagai et al., 2018). We have already made sure that high quality of bread with acceptable attributes could make from bread flour and fresh strain YTPR1 in preliminary investigation. That is, yeast YTPR1 utilized maltose as well as glucose, fructose, and sucrose. Dough prepared using bread flour leavened in all of conditions for making not only French and white breads but also sweet bread, suggesting that yeast YTPR1 can metabolize these fermentable sugars including maltose produced by starch hydrolysis into carbon dioxide and ethanol. In particular, height of loaf on white bread was high as well as that of loaf prepared using commercially available dried yeast. It had a thin skin and crisp skin surface in crust, and had a moist and soft eat feeling in crumb. In comparison with loaf prepared using commercially available dried yeast, vertex of crust showed a whitish and a light brown color. In side of crust, loaf had a light brown color (golden brown color). Moreover, we have been confirmed that strain YTPR1 after 360 days at $-28{ }^{\circ} \mathrm{C}$ of storage satisfactorily produced the same gassing power and ethanol productivity as commercially available baker's dried yeast (Nagai et al., 2018). However, in general, most of wild-type yeasts are inferior to freeze and drying tolerance (Lewis et al., 1997). Hirasawa et al. (2001) tried to improve freeze tolerance of baker's yeast by loading with trehalose using freeze-tolerant and freeze-sensitive compressed baker's yeasts. They reported that intracellular trehalose contents increased with increasing soaking period of yeasts. They also clarified that freeze tolerant ratio in yeasts increased with increasing intracellular trehalose content. Shi et al. (2014) investigated cell survival rate and change of fermentability in dough after frozen storage using six types of baker's yeasts $S$. cerevisiae, and discovered relationship between freeze tolerance of yeasts and intracellular trehalose, amino acids, and glycerol contents. They elucidated that trehalose affected freeze tolerance of yeasts, followed by glutamic acid, arginine, proline, asparagic acid, and glycerol in this order. That is, it seemed that these substances had functions as cryoprotectant or cryosensitizer on yeast cells. It needs to investigate bread-making quality using strain YTPR1 after freezing or drying for use in bread and its related industries. The purpose of study was to compare bread-making quality on S. cerevisiae strain YTPR1 prepared in different conditions to develop high quality of bread with characteristics on wild-type yeast isolated from pear Red Bartlett fruits.

\section{Materials and Methods}

\subsection{Ingredients}

Commercially available baker's dried yeast (Supercamellia) was obtained from Nissin Foods Inc., Tokyo, Japan. Commercially available bread flour and salt were purchased from Kobe Bussan Co., Ltd., Hyogo, Japan. Skim Milk Powder was from Yotsuba Milk Products Co., Ltd., Hokkaido, Japan. Low trans-fatty acids unsalted margarine (ExtremeNeo) was obtained from Marubishi Co., Ltd., Kumamoto, Japan. L-Glutamic acid, glycerol, and sucrose were from Wako Pure Chemical Industries, Ltd., Osaka, Japan. Trehalose (TREHA ${ }^{\circledR}$ ) was from Hayashibara Co., Ltd., Okayama, Japan. All other chemicals were of analytical grade.

\subsection{Yeast}

S. cerevisiae strain YTPR1 isolated from pear Red Bartlett fruits harvested in Yamagata, Japan was used in this study. Loopful strains $(2 \mathrm{mg})$ sub-cultured in YPD plate medium (1\% yeast extract, $2 \%$ polypeptone, $2 \%$ D-glucose, and $2 \%$ agar) were suspended in $1 \mathrm{ml}$ of sterilized water. A $200 \mu \mathrm{l}$ of suspension was incubated with shaking at $120 \mathrm{rpm}$ at $30{ }^{\circ} \mathrm{C}$ for $48 \mathrm{~h}$ in $300 \mathrm{ml}$ of YPD liquid culture medium, and then these were centrifuged at 
$8,000 \mathrm{rpm}$ for $10 \mathrm{~min}$ at $20^{\circ} \mathrm{C}$. Cells were washed with sterilized distilled water. After these were centrifuged at the same condition, cells were washed in the same way. Finally, these treatments were repeated again. Cells (moisture content: about $80 \%$ ) obtained were frozen at $-28{ }^{\circ} \mathrm{C}$ for 7 days (frozen yeast). Apart from it, cells obtained were lyophilized (freeze-dried yeast). The $6 \%$ trehalose, $1 \%$ glycerol, or $1 \%$ L-glutamic acid to $300 \mathrm{ml}$ of YPD liquid culture medium were individually added and sterilized. Loopful strains $(2 \mathrm{mg})$ sub-cultured were applied to the medium, and then were cultured at $30{ }^{\circ} \mathrm{C}$ for $48 \mathrm{~h}$. These were centrifuged at $8,000 \mathrm{rpm}$ for 10 min at $20^{\circ} \mathrm{C}$. Cells obtained were washed with sterilized distilled water, and then these were centrifuged at the same condition. Cells were washed in the same way. These treatments were repeated again, and then yeasts were obtained respectively (trehalose-addition yeast, glycerol-addition yeast, and Glu-addition yeast). These were used for the making bread. As a control, it was done using commercially available baker's dried yeast (commercially available dried yeast).

\subsection{Bread Making}

Ingredients used for making bread are shown in Table 1. Except for freeze-dried yeast and commercially available dried yeast, $13 \mathrm{~g}$ (wet weight) of yeast was used. Dough was prepared using an automatic home bakery (menu: natural yeast dough) (SD-BMS106, Panasonic Corp., Osaka, Japan). Dough obtained was secondary fermented at $35{ }^{\circ} \mathrm{C}$ for $60 \mathrm{~min}$ using a commercially available household steam convection-type oven (menu: fermentation) (Healsio AX-GX2, Sharp Co., Tokyo, Japan). Then, bread loaf was baked at $180{ }^{\circ} \mathrm{C}$ for $30 \mathrm{~min}$ using the same oven [menu: oven (preheat)]. Besides, we have been confirmed that $13 \mathrm{~g}$ (wet weight) of yeast is equivalent to $3 \mathrm{~g}$ of dried ones as cell concentration in this experiment condition from the results of growth tests.

\subsection{Determination of Moisture Content on Crumb}

Breads baked were cooled at room temperature for $1 \mathrm{~h}$, and then moisture contents of crumbs were measured at $140^{\circ} \mathrm{C}$ for 15 min using a Moisture Determination Balance (FD-600, Kett Electric Laboratory, Tokyo, Japan).

\subsection{Determination of Expansion Ratio}

Breads baked were cooled at room temperature for $1 \mathrm{~h}$, and then loaf volumes were determined by rapeseed displacement method (Nagano et al., 2003). Expansion ratio was calculated as the following equation.

Expansion ratio $(\%)=\left[\right.$ Loaf volume after baking $\left(\mathrm{cm}^{3}\right) /$ Dough weight before baking $\left.(\mathrm{g})\right] \times 100$

Specific volume was also calculated as the following equation.

Specific volume $\left(\mathrm{cm}^{3} / \mathrm{g}\right)=$ [Loaf volume after baking $\left(\mathrm{cm}^{3}\right) /$ Loaf weight after baking $\left.(\mathrm{g})\right]$

Table 1. Ingredients used for making bread

\begin{tabular}{lll}
\hline Ingredients & Weight $(\mathrm{g})$ & Baker's \% \\
\hline Wheat flour & 240 & \\
Sucrose & 20 & 8.3 \\
Salt & 4 & 1.7 \\
Skim milk powder & 12 & 5.0 \\
Unsalted margarine & 20 & 8.3 \\
Yeast (dried yeast) & $13(3)$ & $5.4(1.3)$ \\
Water & 170 & 70.8 \\
\hline
\end{tabular}

\subsection{Determination of Decreasing Rate of Baking}

Loaf weight after baking was measured after cooling at room temperature for $1 \mathrm{~h}$. Decreasing rate of baking was calculated as the following equation.

Decreasing rate of baking $(\%)=$

[Dough weight before baking $(\mathrm{g})$ - Loaf weight after baking $(\mathrm{g})] /$ Dough weight before baking $(\mathrm{g}) \times 100$

\subsection{Determination of Breaking Force}

Breads baked were cooled at room temperature for $1 \mathrm{~h}$, and then breaking forces $(\mathrm{N})$ were measured using a rheometer (TPU-2, Yamaden Co., Ltd., Tokyo, Japan) equipped with a wedge-shaped plunger No. 49. Crumb samples $(40 \times 40 \times 20 \mathrm{~mm})$ from center of each slice were compressed up to $25 \%$ deformation at a compression speed of $10 \mathrm{~mm} / \mathrm{s}$. Six replicates of crumb samples were analyzed and the mean was reported. 


\subsection{Color Measurement}

Breads baked were cooled at room temperature for $1 \mathrm{~h}$, and then color analysis was performed using a colorimeter (NR-11A, Nippon Denshoku Industries Co., Ltd., Tokyo, Japan) with illuminant D65 calibrated to black and white standards. CIE $L^{*} a^{*} b^{*}$ system was used as relation to human eye response to color. Color was measured on five different spots in vertex and side of crust and crumb on bread, and results were shown as the mean of these measurements. Moreover, color difference $\left(\Delta E^{*} a b\right)$ was calculated by the following equation as a reference of the color on bread prepared using commercially available dried yeast.

$$
\Delta E^{*} a b=\left[\left(\Delta L^{*}\right)^{2}+\left(\Delta a^{*}\right)^{2}+\left(\Delta b^{*}\right)^{2}\right]^{1 / 2}
$$

Brownness index was also calculated as described by Shittu et al. (2007).

\subsection{Statistical Analysis}

Except for determination of breaking force and color, all experiment results were presented as means of 3 parallel replicates using independent 3 samples.

\section{Results and Discussion}

\subsection{Bread Making}

Breads were baked using bread case (an attachment for an automatic home bakery). As a result, widths of breads were the same $(9.0 \times 12.0 \mathrm{~cm})$ in all cases, but heights were different in the kinds of yeasts. Maximum and minimum heights of loaf prepared using commercially available dried yeast were high about $17.0 \mathrm{~cm}$ and 13.0 $\mathrm{cm}$, respectively (Table 2). Fine-grained bubble membrane uniformly and homogeneously spread in crumb of bread (Figure 1G). In case of frozen yeast, heights of loaf were relatively high about $15.5 \mathrm{~cm}$ and $13.6 \mathrm{~cm}$, respectively (Table 2). Bread had a thin skin and crisp skin surface in crust (Figure 1B), and had a moist and soft eat feeling in crumb. Loaf was spread largely, but its bottom had relatively density (Figure $1 \mathrm{H}$ ). In breads prepared using freeze-dried yeast, trehalose-addition yeast, and glycerol-addition yeast, heights of loaves were low about $8.0 \mathrm{~cm}, 8.5 \mathrm{~cm}$, and $9.5 \mathrm{~cm}$ (maximum height) and about $5.0 \mathrm{~cm}, 6.4 \mathrm{~cm}$, and $7.6 \mathrm{~cm}$ (minimum height), respectively. It suggested that dough could not fully form the gluten network capable of expanding and retain gas produced during fermentation, resulting in bread with lower height. Upper parts of crusts on these loaves were generally soft, but sides were thick, hard, and tough in comparison with that prepared using commercially available dried yeast. Bubble membranes were small and non-uniformly and heterogeneously spread in crumb of breads (Figures 1I-1K). Bottom of these had high density. Bread prepared using glycerol-addition yeast has caused caving/cave-in (Figure 1K). In bread prepared using Glu-addition yeast, heights of loaf were relatively high about $11.0 \mathrm{~cm}$ (maximum height) and $9.0 \mathrm{~cm}$ (minimum height), compared with those prepared using freeze-dried yeast, trehalose-addition yeast, and glycerol-addition yeast (Table 2). Upper part and side of crust on loaf was similar to those prepared using these yeasts, although bubble membrane was small and uniformly and homogeneously spread in crumb of bread (Figure 1L).

\subsection{Bread Property}

\subsubsection{Moisture Content}

Moisture contents of central slice of crumbs (crumb core) on breads were measured after cooling at room temperature for $1 \mathrm{~h}$. As a result, content on bread prepared using commercially available dried yeast was higher than those prepared using freeze-dried yeast, glycerol-addition yeast, and Glu-addition yeast (Table 2). On the other hand, it was lower than those prepared using frozen yeast and trehalose-addition yeast. Moisture contents on breads ranged from about 41.1 to $44.5 \%$, although content on bread prepared using Glu-addition yeast was significantly low about $38.3 \%$ (Table 2). In general, moisture evaporate when crust of bread start to produce during baking, and part of it move to crumb and then condense. After baking, moisture finally decreases to about $5 \%$ in crust and to about $43.5-45.1 \%$ in crumb. In condition used for bread making, it was not sufficient to make doughs ferment using freeze-dried yeast, trehalose-addition yeast, glycerol-addition yeast, and Glu-addition yeast, resulting in difference of moisture contents on crumbs of breads.

\subsubsection{Expansion Ratio}

After cooling at room temperature for $1 \mathrm{~h}$, volumes of loaves were determined by rapeseed displacement method. Volumes ranged from 614.9 to $1832.4 \mathrm{~cm}^{3}$ (Table 2). Among them, volume of loaf prepared using commercially available dried yeast was high and was in decreasing order as follows: frozen yeast, Glu-addition yeast, glycerol-addition yeast, trehalose-addition yeast, and freeze-dried yeast. Expansion ratios of loaves were calculated by ratio between loaf volume after baking and dough weight before baking. Ratio was most highest in 
loaf prepared using commercially available dried yeast, and was in lowering order as follows: frozen yeast, Glu-addition yeast, glycerol-addition yeast, trehalose-addition yeast, and freeze-dried yeast (Table 2).

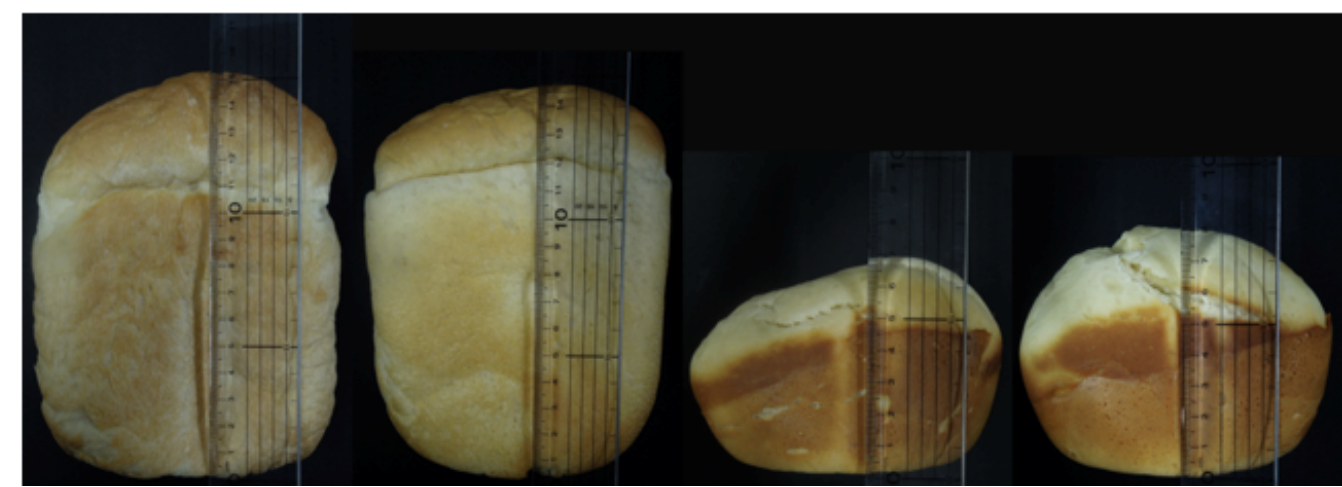

(A)

(B)

(C)

(D)

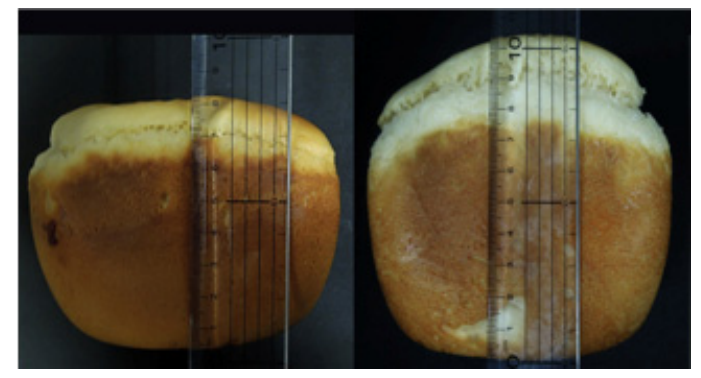

(E)

(F)

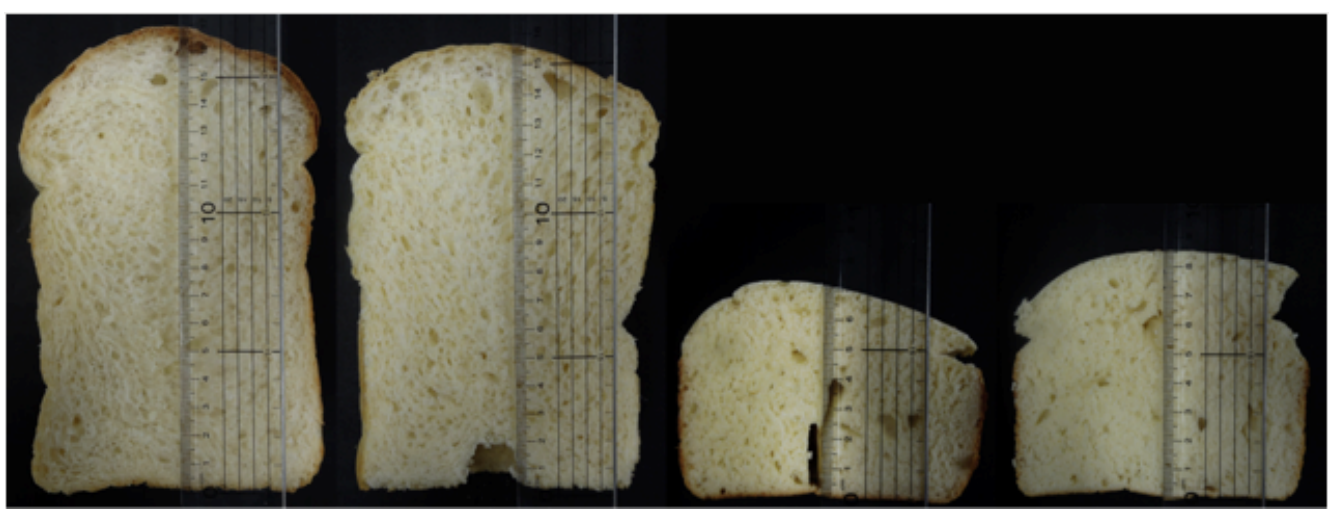

(G)

(H)

(I)

(J)

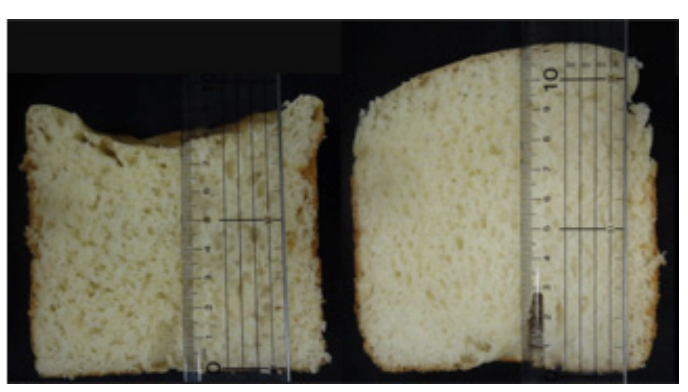

(K)

(L)

Figure 1. Breads (A-F) and its cross sections of crumbs (G-L) using S. cerevisiae strain YTPR1 prepared in different conditions

Note. (A,F) commercially available dried yeast, (B,H) frozen yeast, (C,I) freeze-dried yeast, (D,J) trehalose-addition yeast, (E,K) glycerol-addition yeast, (F,L) Glu-addition yeast. 
Next, weights of loaves were measured using an analytical balance. As a result, weights ranged from 408.0 to $436.1 \mathrm{~g}$ (Table 2). Weight of loaf prepared using freeze-dried yeast was heavy and was in lowering order as follows: Glu-addition yeast, trehalose-addition yeast, glycerol-addition yeast, frozen yeast, and commercially available dried yeast. Specific volumes of loaves were calculated by ratio between loaf volume after baking and loaf weight after baking. Specific volume on loaf prepared using commercially available dried yeast was the highest, and was in lowering order as follows: frozen yeast, Glu-addition yeast, glycerol-addition yeast, trehalose-addition yeast, and freeze-dried yeast (Table 2). As shown in Figure 1, trend could confirm in external appearance of loaves. Specific volume on loaf is one of the most important characteristic because of correspond to softening of crumb on bread. It is used to evaluate quality of breads as a parameter (Boye et al., 2009; Tronsmo et al., 2003). Sluimer (2005) reported that specific volume below $4 \mathrm{~cm}^{3} / \mathrm{g}$ affected quality of bread. Lin et al. (2009) also reported that specific volume of standard bread was $6 \mathrm{~cm}^{3} / \mathrm{g}$, and should not be less than 3.5 $\mathrm{cm}^{3} / \mathrm{g}$, as described by China Grain Products Research and Development Institute. As specific volume on loaf prepared using frozen yeast was $4.21 \mathrm{~cm}^{3} / \mathrm{g}$, it could be determined that this had an excellent quality as well as that prepared using commercially available dried yeast $\left(4.49 \mathrm{~cm}^{3} / \mathrm{g}\right)$.

\subsubsection{Decreasing Rate of Baking}

It is known that decreasing rate of baking on white bread is generally about $10-12 \%$. Hardness of bread increases when the rate is low, but texture leads to be softened when it is high. Decreasing rates of baking on loaves were calculated using breads after cooling at room temperature for $1 \mathrm{~h}$. Rate on loaf prepared using commercially available dried yeast was the same as that prepared using glycerol-addition yeast. However, external appearance and moisture contents of breads were different as shown in Figure 1 and Table 2. It suggested that moisture evaporated in central slice of crumb (crumb core) on bread prepared using glycerol-addition yeast, and part of it moved to crust and then condensed. Rates on loaves prepared using freeze-dried yeasts, trehalose-addition yeast, and Glu-addition yeast were low; moisture did not evaporated from loaves, as it did not fully cause fermentation of dough and expansion of bread during baking. On the other hand, rate on loaf prepared using frozen yeast was highest among them (Table 2), resulting in superior internal and external characteristics such as appearance, crumb homogeneity, and geometry of crumb bubbles (Figures 1B and 1H).

\subsubsection{Breaking Force}

Breaking forces of loaves were measured using crumbs of breads after cooling at room temperature for $1 \mathrm{~h}$. As a result, loaf prepared using frozen yeast showed force about $1.45 \mathrm{~N}$ as well as that prepared using commercially available dried yeast (about $1.52 \mathrm{~N}$ ) (Table 2). Result could be supposed by properties such as loaf weight and volume, moisture content, expansion ratio, specific volume, and weight loss on loaf prepared using frozen yeast. On the contrary, forces of loaves prepared using trehalose-addition yeast, glycerol-addition yeast, and Glu-addition yeast were much higher than that prepared using commercially available dried yeast, indicating more closed internal structure having smaller crumb bubbles and higher crumb cohensiveness for insufficient leavening of doughs (Figures 1J-1L). Surprisingly, force on crumb of loaf prepared using freeze-dried yeast was lowest among these loaves tested, in spite of low loaf volume, expansion ratio, specific volume, and weight loss. It was presumed that center of crumb was soft and outside of it was hard. It meant that the higher the value of breaking force, the higher the loaf hardness. Moore et al. (2006), and Mezaize et al. (2009) reported that hardness of bread correlated well with specific volume; bread with lower specific volume compressed gas cells produced by fermentation, and then increased resistance on deformation of bread and produced higher hardness of crumb.

\subsubsection{Color}

After cooling at room temperature for $1 \mathrm{~h}$, color characteristics of loaves (vertex of crust, side of crust, and crumb) were investigated. In vertex of crust, loaves prepared using frozen yeast, trehalose-addition yeast, glycerol-addition yeast, and Glu-addition yeast had significantly higher $L^{*}$ values, showing a whitish color compared with those prepared using commercially available dried yeast and freeze-dried yeast (Table 2). On the other hand, loaves prepared using frozen yeast, trehalose-addition yeast, glycerol-addition yeast, and Glu-addition yeast had lower $a^{*}$ values, showing a light red color compared with those prepared using commercially available dried yeast and freeze-dried yeast. The $b^{*}$ values were the same about 23.45-29.32, except for loaf prepared using glycerol-addition yeast. $\Delta E^{*} a b$ values were calculated and color differences were evaluated to loaf prepared using commercially available dried yeast as follows: freeze-dried yeast and Glu-addition yeast (appreciable), frozen yeast and trehalose-addition yeast (much), and glycerol-addition yeast (very much). Brownness index was also calculated. As a result, loaves prepared using frozen yeasts and glycerol-addition yeast showed lower index in comparison with that prepared using commercially available dried 
yeast, indicating a light brown color. On the contrary, loaf prepared using freeze-dried yeast with higher index had a darker brown color on vertex of crust.

In side of crust, loaf prepared using frozen yeast with the highest $L^{*}$ value showed a strong whitish color among these loaves (Table 2). Other loaves had significantly lower $L^{*}$ values compared with that prepared using commercially available dried yeast. Loaf prepared using frozen yeast had lowest $a^{*}$ value among these loaves, showing a light red color (Figure 1B). On the contrary, values on other loaves were more than twice as high as that on loaf prepared using commercially available dried yeast. Color difference was evaluated as follows: frozen yeast (much) and freeze-dried yeast, trehalose-addition yeast, glycerol-addition yeast, and Glu-addition yeast (very much). From the results of brownness index, side of crust on loaf prepared using frozen yeast had a light brown color (golden brown color), but those on loaves prepared using freeze-dried yeast, trehalose-addition yeast, glycerol-addition yeast, and Glu-addition yeast had darker brown colors (foxy brown colors).

Table 2. Comparison of bread-making quality on S. cerevisiae strain YTPR1 prepared in different conditions

\begin{tabular}{|c|c|c|c|c|c|c|c|}
\hline & & $\begin{array}{l}\text { Commercially } \\
\text { available } \\
\text { dried yeast }\end{array}$ & Frozen yeast & $\begin{array}{l}\text { Freeze-dried } \\
\text { yeast }\end{array}$ & $\begin{array}{l}\text { Trehalose- } \\
\text { addition } \\
\text { yeast }\end{array}$ & $\begin{array}{l}\text { Glycerol- } \\
\text { addition } \\
\text { yeast }\end{array}$ & $\begin{array}{l}\text { Glu-addition } \\
\text { yeast }\end{array}$ \\
\hline \multicolumn{2}{|l|}{ Dough weight (g) } & 469.0 & 479.0 & 469.0 & 479.0 & 479.0 & 479.0 \\
\hline \multicolumn{2}{|l|}{ Loaf weight (g) } & 408.0 & 412.9 & 436.1 & 425.8 & 416.7 & 435.9 \\
\hline \multicolumn{2}{|l|}{ Loaf volume $\left(\mathrm{cm}^{3}\right)$} & 1832.4 & 1739.7 & 614.9 & 990.6 & 1000.6 & 1077.3 \\
\hline \multicolumn{2}{|c|}{ Loaf height max (cm) } & 17.0 & 15.5 & 8.0 & 8.5 & 9.5 & 11.0 \\
\hline \multicolumn{2}{|c|}{ Loaf height $\min (\mathrm{cm})$} & 13.0 & 13.6 & 5.0 & 6.4 & 7.6 & 9.0 \\
\hline \multicolumn{2}{|l|}{ Moisture (\%) } & 43.4 & 44.5 & 42.1 & 44.1 & 41.1 & 38.3 \\
\hline \multicolumn{2}{|l|}{ Expansion ratio (\%) } & 390.7 & 363.2 & 131.1 & 206.8 & 208.9 & 224.9 \\
\hline \multicolumn{2}{|c|}{ Specific volume $\left(\mathrm{cm}^{3} / \mathrm{g}\right)$} & 4.49 & 4.21 & 1.41 & 2.33 & 2.40 & 2.47 \\
\hline \multicolumn{2}{|l|}{ Weight loss (\%) } & 13.0 & 13.8 & 7.0 & 11.1 & 13.0 & 9.0 \\
\hline \multicolumn{2}{|l|}{ Breaking force $(\mathrm{N})$} & 1.52 & 1.45 & 1.31 & 2.33 & 1.82 & 1.90 \\
\hline \multicolumn{8}{|l|}{ Color } \\
\hline \multirow[t]{3}{*}{ Vertex of crust } & $L^{*}$ & 66.73 & 72.64 & 67.46 & 72.82 & 70.13 & 70.06 \\
\hline & $a^{*}$ & 12.88 & 8.97 & 15.64 & 11.61 & 10.11 & 10.88 \\
\hline & $b^{*}$ & 26.32 & 23.45 & 27.47 & 27.49 & 9.75 & 29.32 \\
\hline \multicolumn{2}{|l|}{$\Delta E^{*} a b$} & - & Much & Appreciable & Much & Very much & Appreciable \\
\hline \multicolumn{2}{|c|}{ Brownness index } & 63.44 & 47.43 & 68.34 & 58.29 & 25.12 & 64.52 \\
\hline \multirow[t]{3}{*}{ Side of crust } & $L^{*}$ & 72.17 & 79.06 & 48.50 & 47.01 & 53.71 & 49.92 \\
\hline & $a^{*}$ & 7.61 & 2.53 & 16.17 & 15.23 & 17.32 & 17.72 \\
\hline & $b^{*}$ & 22.86 & 20.29 & 22.79 & 18.28 & 24.39 & 23.10 \\
\hline \multicolumn{2}{|l|}{$\Delta E^{*} a b$} & - & Much & Very much & Very much & Very much & Very much \\
\hline \multicolumn{2}{|c|}{ Brownness index } & 45.20 & 31.40 & 86.22 & 71.93 & 82.69 & 86.46 \\
\hline \multirow[t]{3}{*}{ Crumb } & $L^{*}$ & 70.88 & 70.40 & 72.79 & 78.25 & 68.00 & 77.07 \\
\hline & $a^{*}$ & -0.35 & 0.03 & -0.28 & -0.74 & -0.33 & -0.44 \\
\hline & $b^{*}$ & -5.18 & -1.01 & 1.56 & 0.46 & 0.73 & 1.34 \\
\hline$\Delta E^{*} a b$ & & - & Appreciable & Much & Much & Much & Much \\
\hline
\end{tabular}

In crumb, loaves prepared using trehalose-addition yeast and Glu-addition yeast had higher $L^{*}$ values than those prepared using commercially available dried yeast, frozen yeast, and glycerol-addition yeast, showing a whitish color (Figures $1 \mathrm{~J}$ and $1 \mathrm{~K}$ ). In comparison to crumbs prepared using commercially available dried yeast and frozen yeast, crumbs prepared using freeze-dried yeast, trehalose-addition yeast, glycerol-addition yeast, and Glu-addition yeast had higher $b^{*}$ values, showing a light yellow color (Figures 1I-1L). Next, $\Delta E^{*} a b$ values were calculated and color differences were evaluated as follows: frozen yeast (appreciable), freeze-dried yeast, trehalose-addition yeast, glycerol-addition yeast, and Glu-addition yeast (much). Color for baked foods such as breads and baked sweets is an important quality indicator. Visual color of crust on loaf is relevant to acceptance and taste (Chattopadhyay et al., 2013). Brown color formation is due to browning by caramelization and Maillard reaction during baking. As shown in Figure 1, loaves prepared using commercially available dried yeast 
and frozen yeast had an even baked color (desirable golden brown color), but those prepared using freeze-dried yeast, trehalose-addition yeast, glycerol-addition yeast, and Glu-addition yeast had an uneven color, particularly undesirable foxy brown color.

Higuchi and Ueda (2006) isolated S. cerevisiae strain from strawberry Amaou fruits harvested in Fukuoka Agriculture and Forestry Research Center, Fukuoka, Japan. They produced the bread experimentally using its strain. Fermentability was inferior to that of commercially available dried yeast. Compared with bread using commercially available dried yeast, bubble membranes were non-uniformly and heterogeneously spread in crumb of bread. Sekiguchi et al. (2008) isolated the strains of Saccharomyces spp. from 138 plants in Hokkaido, Japan. By its 26S RNA sequence analysis, 23 strains were identified as Saccharomyces spp. Among them, three strains S. cerevisiae AHU4438, S. paradoxus AHU4432, and S. Kluyveri AHU4436 with superior gassing power and ethanol productivity were tested for bread making. Colors, shapes, and volumes of these breads were similar to that using commercially available dried yeast. Particulaly, these had flavorful taste with body unlike in the case of commercially available dried yeast. Mase et al. (2014) separated S. cerevisiae strains from flowering plants such as cherry blossom, four o'clock flower, Iris laevigata, Japanese apricot, Japanese hydrangea, Japanese wisteria, pansy, sweet flag and Zinnia in Aichi, Japan. Isolated 14 strains with high gassing power were used in bread making using an automatic home bakery (menu: white bread) (SD-BMS151, Panasonic Corp., Osaka, Japan). They reported that specific volumes of breads were high, about more than $80 \%$ compared with that using yeast (US yeast, Oriental Yeast Co., Ltd., Tokyo, Japan). They concluded that high quality of bread could be produced using isolated strains, as breads had the least preferable sensory qualities in taste and flavor. Shimosaka (2011) made bread using Shirakamikodama yeast and domestic flower with lower protein content (haruyutaka from Hokkaido). Trehalose content of yeast is about 4-5 times as much higher than that of other yeast, expecting production of bread with dampish crumb and natural sweetness without sugar, egg, and butter. Bread had similar loaf volume and lower maximam breaking force in crumb in comparison with those using foreign strong flower (camellia, Nisshin Foods Inc., Tokyo, Japan), indicating bread with softer crumb. By sensory investigation, it showed that bread using Shirakamikodama yeast had crispy crust and dampish crumb. Kamakura and Mayama (2012) separated yeasts from fruits, flowers, and leaves of citrus plants in Tokushima, Japan, and then isolated wild yeast Hanseniaspora meyeri from petal of citrus sudachi by aroma, gassing power, ethanol production, leavening ability in dough using some sugars, optimum growth temperature, and morphological characteristics. Expansion ratios of breads using isolated yeast and commercially available dried yeast were about $220-280 \%$, but height of bread using commercially available dried yeast was higher than that using isolated yeast. On the contrary, width of bread using isolated yeast was high in comparison with that using commercially available dried yeast, indicating that bottom of bread using isolated yeast had relatively high density and bubble membranes were non-uniformly and heterogeneously spread in crumb of it. Color of loaf using isolated yeast, particularly vertex of crust, showed a whitish and a light yellow color, having relatively higher $L^{*}, a^{*}$, and $b^{*}$. Oda et al. (2010) isolated yeast strain AK46 from dough containing fermented Sargentis cherry fruits in the Tokachi District of Hokkaido, Japan, and then identified as S. cerevisiae. They tried to make breads using blended flours with extra strong flour (Yumechikara) and middle-soft flour (Hokushin) (1:1) by no-time bread-making method, straight method, and sponge and dough method. Specific volumes of loaves were as follows in comparison with that using commercially available dried yeast (S. cerevisiae HP216): about 93, 98, and $94 \%$, respectively. By sensory evaluation, breads had the least preferable qualities except for flavor on bread made by no-time bread-making method. Finally, a baker's yeast 'Tokachino' was developed through collaboration of industry, academia, and government (Oda et al., 2012). In these previous papers, it needed to extend the fermentation time, because it took time to fully leaven the dough using wild-type yeast. However, we already confirmed that strain YTPR1 after 360 days at $-28{ }^{\circ} \mathrm{C}$ of storage showed the same bread-making quality as commercially available dried yeast (data not shown). According to the Family Income and Expenditure Survey in 2017 (The Ministry of Internal Affairs and Communications), since bread consumption is very high in Japan, the results in present investigation will be very interesting from the marketing point of view.

\section{Conclusion}

High quality of bread with acceptable attributes could be produced using frozen yeast strain YTPR1 isolated from pear Red Bartlett fruits. On the contrary, it was not suitable to make breads using strain YTPR1 prepared in other condition (freeze-drying and cultivation with $6 \%$ trehalose, $1 \%$ glycerol, or $1 \% \mathrm{~L}$-glutamic acid). That is, these substances had not functions as cryoprotectant or cryosensitizer on yeast cells. 


\section{References}

Bell, P. J. L., Higgins, V. J., \& Attfield, P. V. (2001). Comparison of fermentative capacities of industrial baking and wild-type yeasts of the species Saccharomyces cerevisiae in different sugar media. Letters in Applied Microbiology, 32, 224-229. https://doi.org/10.1046/j.1472-765X.2001.00894.x

Boye, J., Zare, F., \& Pletch, A. (2010). Pluse proteins: Processing characterization, functional properties and applications in food and feed. Food Research International, 43, 414-431. https://doi.org/10.1016/j.foodres. 2009.09.003

Chattopadhyay, S., Raychaudhuri, U., \& Chakraborty, R. (2013). Optimization of soy dessert on sensory, color, and rheological parameters using response surface methodology. Food Science and Biotechnology, 22, 47-54. https://doi.org/0.1007/s10068-013-0007-y

Coutinho, C., Bernardes, E., Felix, D., \& Panek, A. D. (1988). Trehalose as a cryoprotectant for preservation of yeast strains. Journal of Bacteriology, 7, 23-32. https://doi.org/10.1016/0168-1656(88)90032-6

D’Amore, T., Crumplen, R., \& Stewart, G. G. (1991). The involvement of trehalose in yeast stress tolerance. Journal of Industrial Microbiology, 7, 191-196. https://doi.org/10.1007/BF01575882

De Virgilio, C., Hottiger, T., Dominguez, J., Boller, T., \& Wiemken, A. (1994). The role of trehalose systhesis for the acquisition of thermotolerance in yeast. I. Genetic evidence that trehalose is a thermoprotectant. European Journal of Biochemistry, 219, 179-186. https://doi.org/10.1111/j.1432-1033.1994.tb19928.x

Eleutherio, E. C. A., Araujo, P. S., \& Panek, A. D. (1993). Protective role of trehalose during heat stress in Saccharomyces cerevisiae. Cryobiology, 30, 591-596. https://doi.org/10.1006/cryo.1993.1061

Gadd, G. M., Chalmers, K., \& Reed, R. H. (1987). The role of trehalose in dehydration resistance of Saccharomyces cerevisiae. FEMS Microbiology Letters, 48, 249-254. https://doi.org/10.1111/j.1574-6968. 1987.tb02551.x

Gélinas, P., Fiset, G., Leduy, A., \& Goulet, J. (1989). Effect of growth conditions and trehalose content on cryotolerance of baker's yeast in frozen dough. Applied and Environmental Microbiology, 55, 2453-2459.

Higuchi, T., \& Ueda, K. (2006). The yeast utilization as baker's yeast that isolated from Amaou strawberry. Reports of Fukuoka Industrial Technology Center (Vol. 16, pp. 32-34).

Hirasawa, R., Yokoigawa, K., Isobe, Y., \& Kawai, H. (2001). Improving the freeze tolerance of baker's yeast by loading with trehalose. Bioscience, Biotechnology, and Biochemistry, 65, 522-526. https://doi.org/10.1271/ bbb. 65.522

Hottiger, T., Boller, T., \& Wiemken, A. (1987). Rapid changes of heat and desiccation tolerance with changes of trehalose content in Saccharomyces cerevisiae cells subjected to temperature shifts. FEBS Letters, 220 , 113-115. https://doi.org/10.1016/0014-5793(87)80886-4

Kamakura, M., \& Mayama, M. (2012). Bread making property of Hanseniaspora meyeri, one of the wild yeast isolates from petal of Citrus sudachi. Bulletin of Shikoku University, 34, 37-46.

Lewis, J. G., Learmonth, R. P., Attfield, P. V., \& Watson, K. (1997). Stress co-tolerance and trehalose content in baking strains of Saccharomyces cerevisiae. Journal of Industrial Microbiology and Biotechnology, 18, 30-36. https://doi.org/10.1038/sj.jim.2900347

Lin, L., Liu, H., Yu, Y., Lin, S., \& Mau, J. (2009). Quality and antioxidant property of buckwheat enhanced wheat bread. Food Chemistry, 37, 461-467. https://doi.org/10.1016/j.foodchem.2008.07.022

Mackenzie, K. F., Singh, K. K., \& Brown, A. D. (1988). Water stress plating hypersensitivity of yeasts: Protective role of trehalose in Saccharomyces cerevisiae. Journal of General Microbiology, 134, 1661-1666. https://doi.org/10.1099/00221287-134-6-1661

Mase, M., Semii, A., Haba, Y., Ono, N., Yoshino-Yasuda, S., Takamura, R., \& Nakakuki, H. (2013). Bread-making properties of Saccharomyces cerevisiae strains isolated from flowers. Reports of Aichi Center for Industry and Science Technology (Vol. 2, pp. 72-75).

Matsuda, Y., Kudo, S., Koseki, T., Ueki, A., \& Ueki, K. (2005). Isolation of flavor-producing Saccharomyces cerevisiae strains from cherries by the use of phylogenetic analysis. Journal of Brewing Society of Japan, 100, 199-208. https://doi.org/10.6013/jbrewsocjapan1988.100.199 
Mezaize, S., Chevallier, S., Le Bail, A., \& De Lamballerie, M. (2009). Optimization of gluten-free formulations for french-style breads. Journal of Food Science, 74, 140-146. http://doi.org/10.1111/j.1750-3841.2009. 01096.x

Moore, M. M., Heinbockel, M., Dockery, P., Ulmer, H. M., \& Arendt, E. K. (2006). Network formation in gluten-free bread with application of transglutaminase. Cereal Chemistry, 83, 28-36. https://doi.org/ 10.1094/CC-83-0028

Nagai, T., Nakagawa, T., Kai, N., Tanoue, Y., \& Suzuki, N. (2018). Characterization of 2-deoxy-D-glucose tolerant Saccharomyces cerevisiae strain YTPR1 from fruits harvested in Yamagata, Japan. Journal of Agricultural Science and Technology, submitted for publication.

Nagano, H., Okamoto, J., Kato, M., Nagashima, N., \& Omori, M. (2003). Experiment of Cookery Science by the Flow Chart (2nd ed., pp. 34-35). Tokyo: Chijinshokan.

Nagata, S. (2017). Retrieved from http://www.cc.kochi-u.ac.jp/ hmura/research.html

Oda, Y., Mikuno, D., Tajima, K., \& Yamauchi, H. (2010). Characterization of an alternative baking strain of Saccharomyces cerevisiae isolated from fermented cherry fruits by the analysis of SUC2 gene. Food Science and Technology Research, 16, 45-50. https://doi.org/10.3136/fstr.16.45

Oda, Y., Yamauchi, H., \& Tamura, M. (2012). Development of baker's yeast “Tokachino" through Collaboration of Industry, Academia and Government. Nippon Shokuhin Kagaku Kogaku Kaishi, 59, 1-5. https://doi.org/ 10.3136/nskkk.59.1

Panek, A. C., Vania, J. J. M., Paschoalin, M. F., \& Panek, D. (1990). Regulation of trehalose metabolism in Saccharomyces cerevisiae mutants during temperature shifts. Biochimie, 72, 77-79. https://doi.org/10.1016/ 0300-9084(90)90176-H

Pearce, D. A., Rose, A. H., \& Wright, I. P. (1989). Trehalose and trehalase in active dried yeast. Yeast, 5, S453-S457.

Sekiguchi, A. (2008). Studies on improvement of "Minowa" yeast. Reports of Gunma Industrial Technology Ceter (pp. 9-12).

Sekiguchi, S., Tanaka, M., Takahashi, A., \& Asano, K. (2008). Isolation of Saccharomyces spp. from plants in Hokkaido and their characteristics for bread making. Journal of Brewing Society of Japan, 103, $125-134$. https://doi.org/10.6013/jbrewsocjapan1988.103.125

Shi, X., Miao, Y., Chen, J. Y., Chen, J., Li, W., He, X., \& Wang, J. (2014). The relationship of freeze tolerance with intracellular compounds in baker's yeasts. Applied Biochemistry and Biotechnology, 172, 3042-3053. https://doi.org/10.1007/s12010-014-0744-2

Shimosaka, C. (2011). Preparation method and puffing behavior of bread with Shirakamikodama yeast. Journal of Cookery Science of Japan, 44, 223-230. https://doi.org/10.11402/cookeryscience.44.223

Shittu, T. A., Raji, A. O., \& Sanni, L. O. (2007). Bread from composite cassava-wheat flour: I. Effect of baking time and temperature on some physical properties of bread loaf. Food Research International, 40, $280-290$. https://doi.org/10.1016/j.foodres.2006.10.012

Slaughter, J. C., \& Nomura, T. (1992). Intracellular glycogen and trehalose contents as predictors of yeast viability. Enzyme and Microbial Technology, 14, 64-67. https://doi.org/10.1016/0141-0229(92)90028-M

Sluimer, P. (2005). Principle in brief (Principles of breadmaking) (pp. 1-15). St. Paul: American Association of Cereal Chemists.

Takagi, H., Sakai, K., Morida, K., \& Nakamori, S. (2000). Proline accumulation by mutation or disruption of the proline oxidase gene improves resistance to freezing and desiccation stresses in Saccharomyces cerevisiae. FEMS Microbiology Letters, 184, 103-108. https://doi.org/10.1111/j.1574-6968.2000.tb08998.x

Takagi, H., Takaoka, M., Kawaguchi, A., \& Kubo, Y. (2005). Effect of L-proline on sake brewing and ethanol stress in Saccharomyces cerevisiae. Applied and Environmental Microbiology, 71, 8656-8662. https://doi.org/10.1128/AEM.71.12.8656-8662.2005

Tronsmo, K., Faergestad, E., Schofield, J., \& Magnus, E. (2003). Wheat protein quality in relation to baking performance evaluated by the Chorleywood bread process and a hearth bread baking test. Journal of Cereal Science, 38, 205-215. https://doi.org/10.1016/S0733-5210(03)00027-4 


\section{Copyrights}

Copyright for this article is retained by the author(s), with first publication rights granted to the journal.

This is an open-access article distributed under the terms and conditions of the Creative Commons Attribution license (http://creativecommons.org/licenses/by/4.0/). 